\title{
AC 2009-225: CONVERSION OF AN EXISTING CAR TO A RECHARGEABLE ELECTRIC VEHICLE
}

\section{Janak Dave, University of Cincinnati}

Janak Dave PhD, PE is a Professor in the department of Mechanical Engineering Technology at the University of Cincinnati. He obtained his MS and PhD in Mechanical Engineering from the University of Missouri at Rolla. He has presented papers at ASEE Annual Conferences, ASME International Congress, and several International conferences and conducted $\mathrm{CAD} / \mathrm{CAM} / \mathrm{CAE}$ workshops nationally and internationally. He has held various positions in EDG and DEED divisions of ASEE, and local and national committees of ASME.

\section{Janet Dong, University of Cincinnati}

Janet Dong, Ph.D. is an assistant professor in the department of Mechanical Engineering Technology at University of Cincinnati. She holds a BS degree in Mechanical Engineering and a MS degree in Manufacturing Engineering. She received her Ph.D. in Mechanical Engineering from Columbia University in 2003. Her academic interests include CAD/CAM, manufacturing engineering technology, process planning, control and automation, robotics, engineering education and research, and manufacturing applications in the dental field. 


\title{
Conversion of an Existing Car to a Rechargeable Electric Vehicle
}

\begin{abstract}
There is a need to improve the efficiency and reduce tailpipe emissions while maintaining the affordability of vehicles that are currently used for daily commuting. As petroleum deposits dwindle, automobile populations soar, gas prices inflate and cities become choked with combustion emissions, the internal combustion engine (ICE) is increasingly becoming the victim of its own success. Assuming that private automobiles continue to be a vital link in modern societies, they must become cleaner and more energy efficient.

Students working toward a baccalaureate degree in Mechanical Engineering Technology at the University of Cincinnati are required to complete a "Design, Build, and Test" Senior Capstone Design Project. During the 2006-2007 academic year two MET students proposed, for their "senior project", to convert an existing Mustang automobile to a rechargeable electric vehicle (REV) for commuter transportation. They derived a great deal of personal satisfaction by working on a technically complex project.

This paper will give a short description of the Mechanical Engineering Technology senior capstone design course sequence at University of Cincinnati, the list of pre-requisites of this sequence, and describe the 2006-2007 REV project, providing information about an affordable, efficient and cleaner method for commuter transportation.
\end{abstract}

\section{Introduction}

Completing a senior capstone design project is a graduation requirement for all students in the Mechanical Engineering Technology (MET) department at the College of Applied Science, University of Cincinnati (UC). The capstone process consists of a four-course sequence resulting in a working product. These courses are designed to facilitate student synthesis and the application of knowledge and skills they have acquired prior to their senior year. This fourcourse sequence also requires students to utilize their abilities to solve open-ended problems and to prepare them for the transition from the academic world into an industrial environment.

The capstone project consists of designing, building, and testing a prototype for a product or process. At the completion of their senior capstone project, students will have acquired the following skills, which will apply to their professional careers.

1. Synthesizing knowledge from early courses

2. Starting from concept to production of a working prototype

3. Project management

4. Time management

5. Dealing with vendors

6. Oral communication with both technical and non-technical audiences

7. Writing a formal project report 


\section{Senior Capstone Project}

The four-course senior project sequence consists of Senior Seminar, Senior Design Project I, Senior Design Project II, and Senior Communications. The first three courses are offered by the MET department, and the fourth is by the Humanities, Media and Cultural Studies (HMCS) department. This sequence constitutes $6.75 \%$ of the MET baccalaureate degree requirements. It is also required that the students present their project at the annual Technical Exposition (Tech Expo). Below is a short description of each course and the required pre-requisites.

\section{Pre-requisites:}

In addition to statics, kinematics, dynamics, mechanics of materials, and engineering design graphics courses, MET students take three design courses, one each year during their sophomore, junior, and senior years. This sequence is: Design of Machine Elements, Mechanical Design, and Product Development. The main emphasis of the Product Development course is to teach systematic design methodology, and expose students to the tools and techniques currently practiced in industries, such as Quality Function Deployment (QFD), Concurrent Engineering, Design for Assembly (DFA), Design for Manufacturing (DFM), and Project Management. This enables students to apply some of these practices to their senior project.

\section{Senior Seminar:}

Students are required to propose ideas for their senior project in Senior Seminar. These ideas may originate from industry, departmental faculty, national competitions, by themselves, or any other sources. By the end of this course, all students must have a written, detailed project proposal, which includes research, cost estimate, customer surveys, and tentative schedules, etc. Students are assigned a project advisor who works with them in finalizing the proposal. The relationship between the advisor and students is very similar to a project engineer and her/his supervisor/manager.

\section{Senior Design Project I:}

Admission to Senior Design I is contingent upon the successful completion and approval of the proposal submitted in Senior Seminar. Students use systematic design methodology to come up with final technical specifications for their product. They generate conceptual designs, and select the best concept using weighted objective or the Pugh method. They also do a detailed design and analysis of all parts, including generating working drawings and a bill of materials. The analyses may consist of stress, kinematic, heat transfer, and DFM, etc. These activities are documented in two different forms: weekly reports to the advisor and a comprehensive, professionally written, interim design report at the end of the quarter.

\section{Senior Design Project II:}

During Senior Design Project II, students are expected to machine or purchase the designed parts and assemble these into a prototype. The parts needing complex, precise machining that can not be machined using university equipment are outsourced. The finished prototype is tested and 
modified to meet or exceed the technical specifications as defined by the students in their design report.

\section{Senior Communications:}

The Senior Communications component of this sequence prepares students for oral communications and presentations to all audiences, both technical and non-technical. They also learn how to write a professional, technical report and apply it to their individual projects.

\section{Tech Expo:}

Local industries, employers, families, alumni, and the media are invited to the college sponsored Technical Exposition (Tech Expo) held during the month of May. Seniors from the College of Applied Science (CAS) display, demonstrate and discuss their projects with interested parties. Industry judges, using very exacting criteria, evaluate departmental projects and select departmental winners. One project, chosen from the best project of each CAS, degree granting department will then be awarded during the Tech Expo. The winning project in the year of 20062007 was the REV project.

\section{REV Project}

Environmental pollution, global warming, along with high gasoline prices, are some of the concerns for today's consumer. Carbon dioxide and other chemical pollutants emitted by automobiles result in environmental degradation. According to the Intergovernmental Panel on Climate Change (IPCC), the report on human activities (2007), including burning fossil fuels, are the likely cause of global warming, see reference ${ }^{[1]}$ for details.

As their Senior Capstone project, two MET students (Paul Carhuatanta and Adam Newman) chose to convert a combustion engine automobile to an electric vehicle that would reduce the emission of carbon dioxide during commuter transportation and city pollution. Electric vehicles emit no $\mathrm{CO}_{2}$, and are more efficient and quieter compared to traditional combustion engine vehicles. This project converted a Ford Mustang with an Internal Combustion Engine (ICE) into a battery-powered, rechargeable electric vehicle (REV). Converting an existing ICE platform to electric power was more affordable than building one from the ground up.

According to the US Census Bureau, the average person commutes (round trip) approximately 34 miles per day and drives at an average speed of 60 miles per hour (mph). This commute produces $6.664 \mathrm{lbs}$ of $\mathrm{CO}_{2}$ per commute, according to the U.S. Environmental Protection Agency (EPA). An electric vehicle will comply with the current automotive and safety standards and eliminate the $\mathrm{CO}_{2}$ emissions. If more commuters would use an electric vehicle, there would be less emission of $\mathrm{CO}_{2}$ in urban areas. With these parameters, the students decided to convert an existing Ford Mustang to a REV as their senior capstone project. 


\section{REV Features:}

The REV will have the following features

- Two passengers

- Range greater than 35 miles between charges

- Top speed of $60 \mathrm{mph}$ and higher

- $\quad$ Easy to recharge

- Meet current safety standards

- Power brakes

The important components in REV are the electric motor, speed controller, batteries and charger, coupler, and driveline. Their functions are described below.

\section{Electric motor}

A critical part of an REV is the electric motor, which has a $90 \%$ conversion efficiency at high $\mathrm{rpm}$. The electric motor is responsible for the propulsion system. Meaning, it provides sufficient horse-power (hp) and torque to move the vehicle. The motor selected must be able to keep continuously supply $29 \mathrm{hp}$ and a peak of $69 \mathrm{hp}$ at a maximum speed of $60 \mathrm{mph}$.

\section{Controller}

The controller should provide smooth, silent, cost-effective control of the motor speed and torque. Additional features used in selecting the controller are variable drive and brake control, high efficiency (for reduced motor and battery losses) and silent operation, thermal protection and compensation circuit, as well as providing both under and over-temperature cutback, and steady current limit throughout the entire operating range.

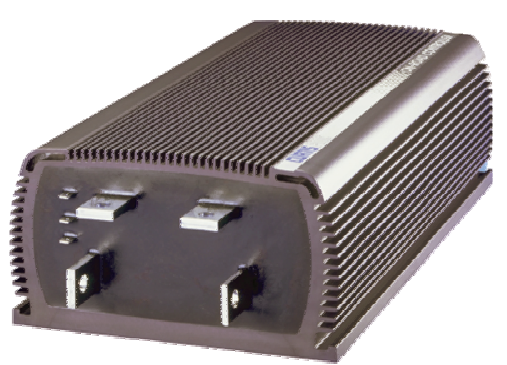

Figure 1. Curtis Controller $1231 \mathrm{C}$

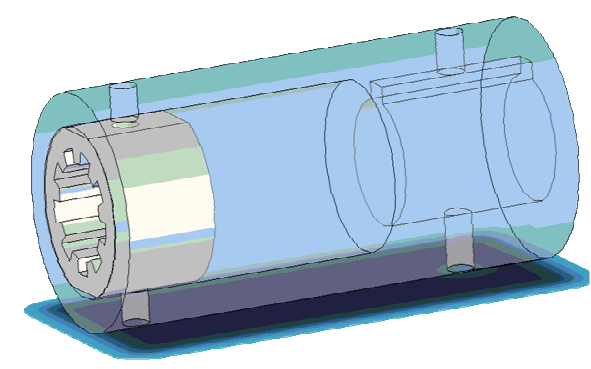

Figure 2. Coupler Design

\section{Charger}

The charger is a very important part of the conversion as its main function is to charge the batteries to 144VDC from 115VAC.

\section{Battery}

The battery selection determines many things--the motor HP output, range between charges, and cost of conversion. Batteries also greatly contribute to the total vehicle weight. Lead acid batteries were selected for their lower cost and availability. A 144v system consisting of a dozen 
$12 \mathrm{v}$ batteries was selected. These batteries total $792 \mathrm{lbs}$., yielding an approximate range of 40 miles per charge. This system has the highest power to weight ratio and is the least expensive.

\section{Coupler}

A coupler (Figure 2) is the mechanical device that connects the electric motor to the manual transmission. This coupler was able to withstand the peak HP of the motor. The material selected for the coupler was low carbon steel.

\section{Driveline}

The motor mount was able to support the weight of electric motor, the adaptor plate, spacer plate, motor mount plate, and transmission. The top of the motor mount on each side was mounted to the existing motor mount pads with a thick piece of rubber to reduce vibrations. The transmission adaptor plate was made of thick aluminum plate. This plate adapted the transmission bell-housing bolt pattern to the motor mount plate. The motor mount plate and spacer plate were both aluminum plate. The three plates were mounted together to provide a space between the transmission bell-housing and the electric motor allowing clearance for the shafts, see Figure 3.

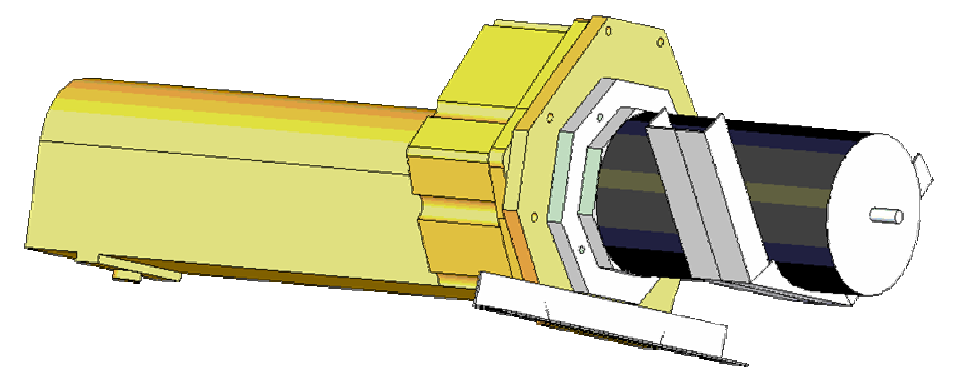

Figure 3. Transmission Mount

\section{Design Process:}

Customers were surveyed and their needs included in REV specifications. Different concepts for motor mount and driveline were analyzed using QFD (Quality Function Deployment) and weighted decision matrix before the final concept selection. For the motor mount, there were three options-steel plate with one spacer, cradle type, or steel plate with three spacers. These were analyzed for cost, weight, and manufacturing time.

\begin{tabular}{|c|c|c|c|c|c|c|c|c|c|c|c|c|}
\hline \multicolumn{13}{|c|}{ Weighted Decision Matrix - Motor Mount } \\
\hline & \multicolumn{4}{|c|}{ Steel Plate w/ 1 piece spacer } & \multicolumn{4}{|c|}{ Cradle type } & \multicolumn{4}{|c|}{ Steel Plate w/ 3 piece spacer } \\
\hline Feature & weight & magnitude & rank & score & weight & magnitude & rank & score & weight & magnitude & rank & score \\
\hline cost & 0.5 & $\$ 100$ & 3 & 1.5 & 0.5 & $\$ 25$ & 8 & 4 & 0.5 & $\$ 50$ & 6 & 3 \\
\hline weight & 0.3 & $10 \mathrm{lbs}$ & 5 & 1.5 & 0.3 & $5 \mathrm{lbs}$ & 8 & 2.4 & 0.3 & $10 \mathrm{lbs}$ & 5 & 1.5 \\
\hline $\begin{array}{l}\text { manufacturing } \\
\text { time }\end{array}$ & 0.2 & 6 hrs & 2 & 0.4 & 0.2 & 2 hrs & 6 & 1.2 & 0.2 & $3 \mathrm{hrs}$ & 4 & 0.8 \\
\hline & & & & 0 & & & & 0 & & & & 0 \\
\hline & & & sum & 3.4 & & & & 7.6 & & & & 5.3 \\
\hline & & & & & & & & best option & & & & \\
\hline
\end{tabular}

Figure 4. Weighted Decision Matrix 


\begin{tabular}{|c|c|c|c|c|c|c|c|c|c|c|c|c|c|c|c|c|}
\hline $\begin{array}{l}9=\text { Strong } \\
3=\text { Moderate } \\
1=\text { Weak }\end{array}$ & 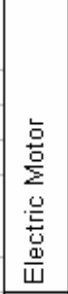 & 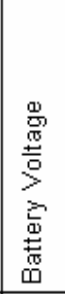 & 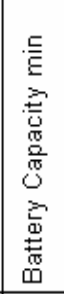 & 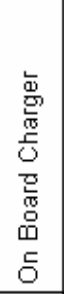 & 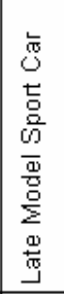 & 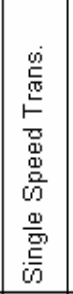 & 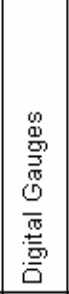 & 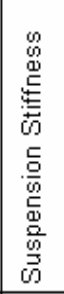 & 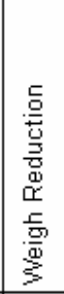 & 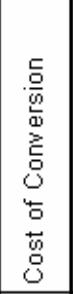 & 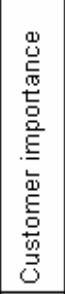 & 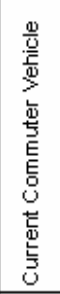 & 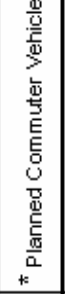 & 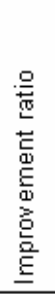 & 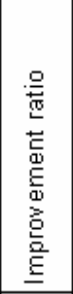 & 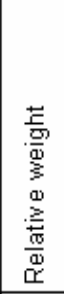 \\
\hline \multicolumn{17}{|l|}{ Aesthetics } \\
\hline styling/appearance & & & & & 9 & & 3 & & 1 & & 4.1 & 3.9 & 5.0 & 1.3 & 5.3 & 0.07 \\
\hline easy to read gauges & & & & & & & 9 & & & & 4.1 & 4.1 & 4.1 & 1.0 & 4.1 & 0.05 \\
\hline engine noise & 9 & & & & & & & & & & 4.1 & 3.2 & 5.0 & 1.6 & 6.4 & 0.08 \\
\hline \multicolumn{17}{|l|}{ Features } \\
\hline interior ergonomics & & & & & 1 & & 3 & & 1 & & 4.1 & 3.2 & 3.2 & 1.0 & 4.1 & 0.05 \\
\hline \multicolumn{17}{|l|}{ Performance } \\
\hline acceleration 0-70mph & 9 & 9 & 1 & & 1 & 3 & & & 3 & & 4.1 & 3.6 & 3.6 & 1.0 & 4.1 & 0.05 \\
\hline top speed & 3 & 9 & 1 & & 1 & 3 & & & 3 & & 3.6 & 3.5 & 3.5 & 1.0 & 3.6 & 0.05 \\
\hline handling & & & & & 3 & & & 9 & 9 & & 4.1 & 3.6 & 3.6 & 1.0 & 4.1 & 0.05 \\
\hline range (miles per tank) & 3 & 3 & 9 & & 1 & 3 & & & 9 & & 4.5 & 3.7 & 3.7 & 1.0 & 4.5 & 0.06 \\
\hline braking & & & & & 1 & & & 3 & 3 & & 4 & 3.7 & 3.7 & 1.0 & 4.0 & 0.05 \\
\hline shifting gears & 3 & & & & & 9 & & & & & 3.9 & 3.4 & 5.0 & 1.5 & 5.7 & 0.07 \\
\hline \multicolumn{17}{|l|}{ Cost } \\
\hline initial cost & & & & & & & & & & 9 & 4.6 & 3.7 & 5.0 & 1.4 & 6.2 & 0.08 \\
\hline maintenance cost & 3 & 3 & 3 & & & 1 & & & & & 4.4 & 3.8 & 3.8 & 1.0 & 4.4 & 0.06 \\
\hline cost to fill tank & 3 & 3 & 9 & & & & & & & & 4.7 & 3.8 & 5.0 & 1.3 & 6.2 & 0.08 \\
\hline \multicolumn{17}{|l|}{ Miscellaneous } \\
\hline overall safety & & 1 & 1 & & 1 & & & 3 & 3 & & 4.5 & 3.9 & 3.9 & 1.0 & 4.5 & 0.06 \\
\hline emissions & 9 & 1 & 1 & & & & & & & & 3.9 & 3.6 & 5.0 & 1.4 & 5.4 & 0.07 \\
\hline refueling convenience & & & & 9 & & & & & & & 4.1 & 3.6 & 5.0 & 1.4 & 5.7 & 0.07 \\
\hline Absolute Importance & 2.53 & 1.35 & 0.91 & 0.65 & 1.08 & 1.18 & 0.83 & 0.8 & 1.73 & 0.71 & 11.8 & & & & 78.3 & 1.00 \\
\hline Relative Importance & 0.21 & 0.11 & 0.08 & 0.06 & 0.09 & 0.10 & 0.07 & 0.07 & 0.15 & 0.06 & & & & & & \\
\hline Commuter Vehicle Currently on market & $>0$ & & & & & 4 & & & & 16000 & & & & & & \\
\hline Direction of improvement & $\uparrow$ & $\mathrm{X}$ & $\mathrm{X}$ & $\mathrm{X}$ & $\mathrm{X}$ & $\downarrow$ & $\mathrm{X}$ & $\mathrm{X}$ & $\mathrm{X}$ & $\downarrow$ & & & & & & \\
\hline Target & 0 & & & & & 1 & & & & 8540 & & & & & & \\
\hline Units & $\mathrm{CO}_{2}$ & & & & & Gears & & & & $\$$ & & & & & & \\
\hline
\end{tabular}

Figure 5. Quality Function Deployment

\section{Fabrication:}

Before it was used as an REV, the 1994 Ford Mustang required the following processes. First was the removal of all unwanted components to reduce the complexity, such as

- ICE

- The automatic transmission

- The ICE wiring harness

- The gas tank

- Fuel lines, hydraulic lines, and cooling lines,

- Backseat

The next step was to convert the power steering to manual steering. The power steering rack was removed and a new manual steering rack was installed. New steering rack bushings and tie rod ends were also installed. The third step was to clean all areas of the car, including the engine compartment. This was done using degreasing products and sanding equipment. A coat of primer was then applied to all metal surfaces to prepare for future painting. The final step was to restore 
the braking system. The rear drum brakes were disassembled and new hardware and brake shoes were installed. The front disk brakes were disassembled, cleaned, and new pads were installed. The emergency brake was activated.

\section{Assembly:}

After machining all of the designed parts, they were assembled in a specific sequence. The adaptor plate was first bolted to the transmission bell housing. The transmission was then slid under the car and raised into place with a hydraulic floor jack. The factory rear mount was used and bolted to the transmission. The student designed front transmission mount was secured to the frame using a rubber spacer, which provided damping, and then was bolted to the adaptor plate. The transmission was then self-supported, which is an improvement to the factory design because the motor was able to be installed separately. The factory design relies on the motor to support the front of the transmission.

To install the motor, the spacer plate and motor mount plate were first secured to the motor. The coupler was installed on the shaft and secured. Then the motor was installed by lowering the motor with a hydraulic lift onto the front motor mount. The motor was then shifted towards the transmission until the adaptor plates met and the coupler spline fitted over the transmission spline. The motor was rotated until the bolt holes matched and then secured to the adaptor plate. Eight of the batteries were placed in the area of the back seat, and the remaining four were placed in the original engine compartment. This allows a more equal weight distribution.

Figure 6 and 7 shows the component layout and an actual photograph of the prototype.

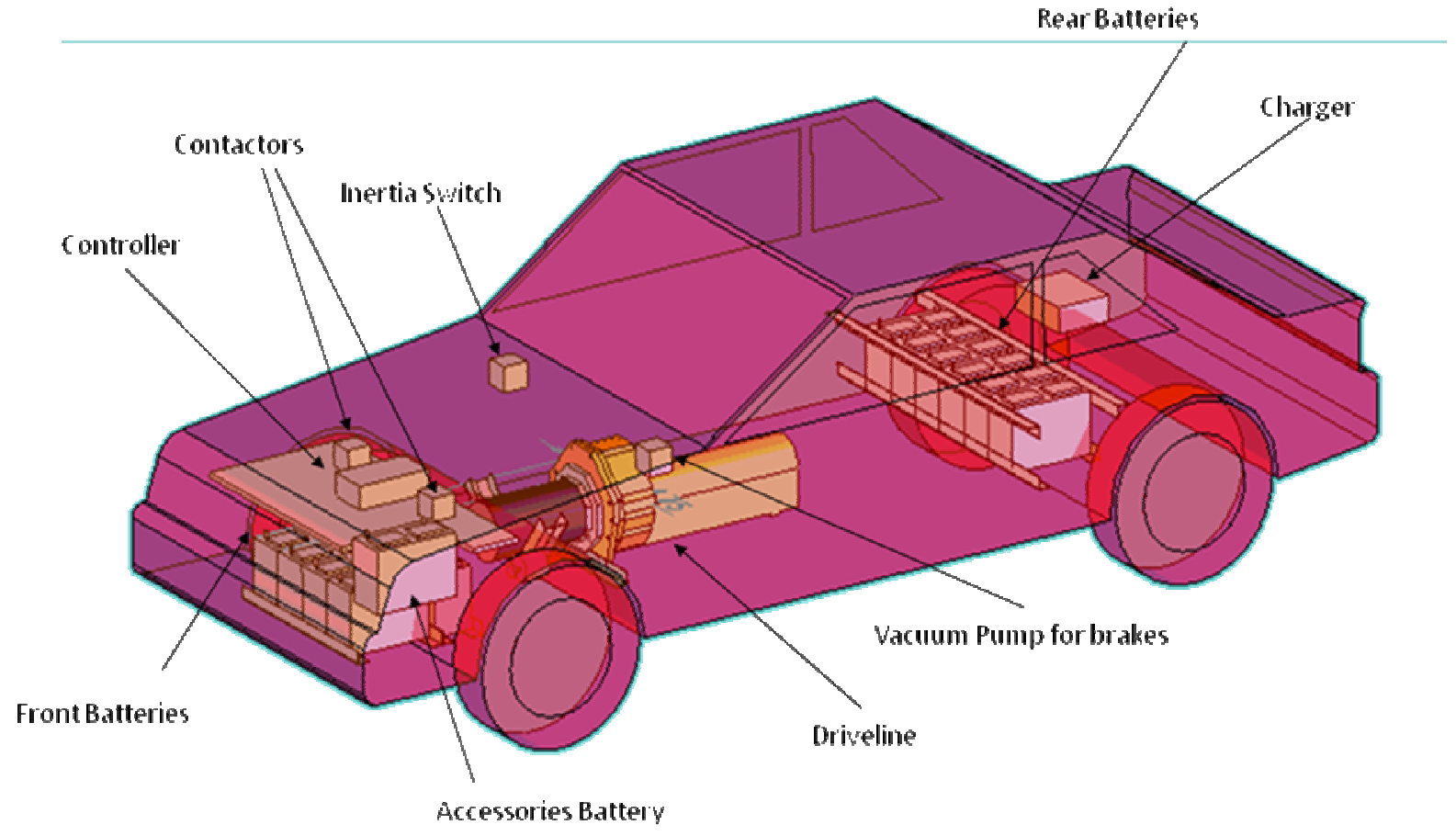

Figure 6. REV Components Layout 


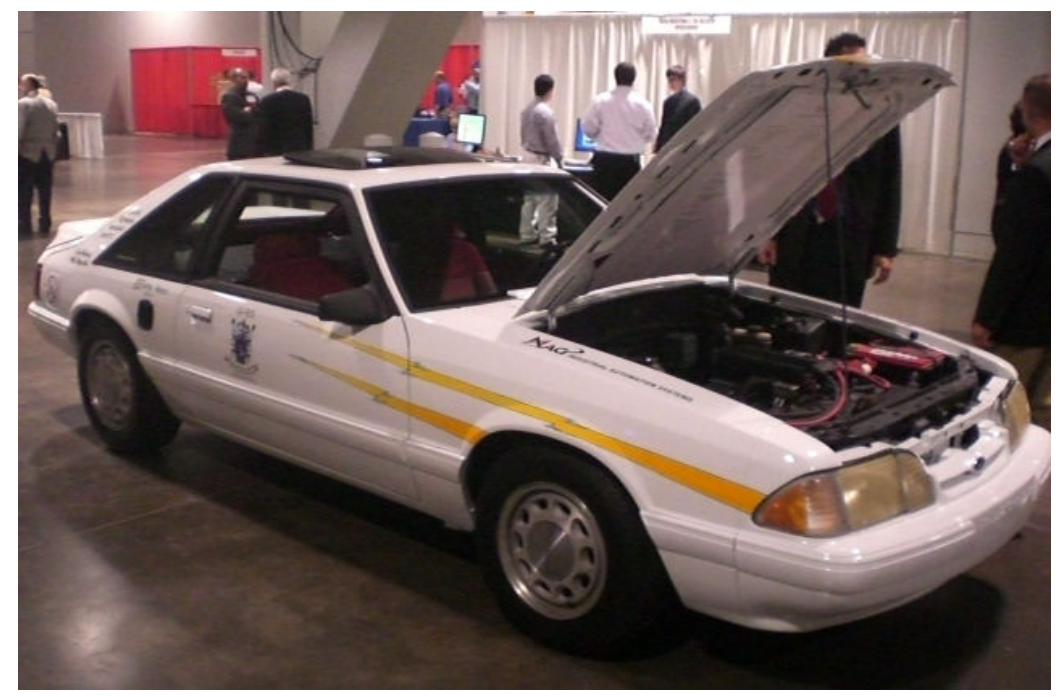

Figure 7. REV Photograph at TechExpo 2007

\section{Testing:}

There were two, separate tests. The vehicle was tested near Cincinnati on Interstate 71 using two passengers. It reached a maximum speed of $61.7 \mathrm{mph}$ as measured by the onboard GPS and had a range of 40 miles between charges. The vehicle handling on the highway was similar to an ICE automobile. The range test was also done in a parking lot.

To measure the success of this project, proof of design consisted of a benchmark for top speed, range, and total conversion cost. The range benchmark between charges, on level pavement while transporting $300 \mathrm{lbs}$., was to be greater than 20 miles measured by the GPS. Using a large, empty parking lot, the car was range tested for over two hours. With the batteries starting with an average of 13.5 volts, which is less than a full charge, the car registered 24 miles with the onboard GPS before a re-charge was required. The parking lot was level, but did not allow for speed to exceed $45 \mathrm{mph}$.

The top speed benchmark was to be greater than 60mph measured by the GPS. The top speed proven on the interstate was $61.7 \mathrm{mph}$ according to the onboard GPS. To verify this speed, a second car followed with a video camera, recording the test.

Before testing on a public road, students had to obtain the insurance for the car. Many difficulties were encountered, most regarding the value of the car.

\section{Conclusion}

The REV project was one of the more complex senior design projects in the MET department during the academic year of 2006-2007. The vehicle met all of the current safety requirements, with a total cost that was under $\$ 7,000.00$. As the vehicle is still on the road, it was a technically successful project. Both students addressed the environmental issues facing some of our cities. 
Besides the research needed for design, analysis, and building the vehicle, the team obtained invaluable experience in fund raising, working as a team, time management, and oral presentations to a group of industry judges and a non-technical audience, writing individual reports as well a team project report. They were awarded first prize by the MET Department and the College of Applied Science "Best of Tech Expo in 2007. Some of the pros of a complex project are increased student self confidence, ability to handle the interviews by electronic and print media, etc. For the institution, higher media attention can result in the recruitment of better students and donations. Some of the cons are demands of more resources (monetary in-kind), longer lead time and devoted students etc.

\section{Bibliography}

1. www.ipcc.ch, the Intergovernmental Panel on Climate Change (IPCC) 2007 Report on Human Activities.

2. The 2007 Rechargeable Electric Vehicle Conversion Design Report - submitted to University of Cincinnati, Adam Newman, June 2007.

3. The 2007 Rechargeable Electric Vehicle Conversion Design Report - submitted to University of Cincinnati, Paul Carhuatanta, June 2007.

4. Design - Build - Test - BUV - A Senior Capstone Design Project, Janak Dave, Janet Dong, ASEE Annual Conference and Expositions, 2007.

5. Creation, Development and Approval of Design, Build, and Test Senior Design project, Janak Dave, Thomas Boronkay, ASME International Mechanical Engineering Congress and Exposition (IMECE), 2001.

6. Senior Capstone Design Project in the Mechanical Engineering Technology Curriculum, Thomas Boronkay, Janak Dave, ASME International Mechanical Engineering Congress and Exposition (IMECE), 2001. 